\title{
EDUCATION AS A SPEAKER VARIABLE
}

\author{
Enam Al-Wer \\ University of Essex, UK
}

\section{Introduction}

One of the main concerns of variationist (socio)linguistics as developed by Labov is to understand language change. It does this on the basis of empirically collected linguistic data. An important aim of this approach is to understand the structure of variability by establishing correlations between the social characteristics of the speakers (the social variables) and use of linguistic forms. Sociolinguistics, therefore, pays a good deal of attention to methodology, and it is a priori for the social variables to be based on a realistic and meaningful categorisation of speakers.

The importance of methodological issues in modern sociolinguistics is reflected in the fact that researchers have continually engaged in refining the methodological practices at various stages. For instance, consider the developments in the treatment of data from the English-speaking communities: from a model broadly based on socioeconomic class (Labov 1972, Trudgill 1974), to one based on smaller, locally based social network clusters (L. Milroy 1987, Cheshire 1982; see also the insightful article by L. Milroy \& J. Milroy 1992). The continuing debates concerning the concept of social class, ethnicity and gender as speaker variables have had a profound knock-on effect on sociolinguistic theory, as well as on methodology. The work of Penelope Eckert in particular has made invaluable contributions to our understanding of the relationship between speakers' linguistic behaviour and their position in social space, the treatment of speaker variables, such as age and gender, and the inter-dependency of social categories and speaker variables (see Eckert 1989 \& 1999). 
Analysis of variation in spoken Arabic has been clearly influenced by the 'new ways of thinking' in sociolinguistics in general. A case in point is the topsy-turvy manner in which the interpretation of patterns of gender differentiation in spoken Arabic has been turned. In variation studies on spoken Arabic, the female speakers have been found to adhere to Classical Arabic norms (especially at the levels of phonology and morphosyntax) less often than the male speakers. These findings were initially assumed to contradict the pattern found in western communities especially during the 1970's and early 1980's, where, other things being equal, women were found to use the standard features more often than men. The confusion in the interpretation of Arabic data principally stemmed from the false assumption that Classical Arabic as a standard variety was involved in the hierarchical arrangement of the target features in the spoken dialects (on this subject, see the important article by M. Ibrahim 1986, which has introduced a more realistic approach to the treatment of data from spoken Arabic; see also Haeri 1987, and Al-Wer 1997).

In order for studies on Arabic to be based on a congruous approach, which goes beyond making statements about correlations between linguistic structure and social structure, however interesting these correlations may be, it is important to 'revisit' the basics of the methodology. In this article, I take issue with 'education' as a speaker variable. This variable is unanalysed in terms of its denotations, but is found in the early large scale investigations, such as Schmidt 1974, Abdel-Jawad 1981, Holes 1987 and Jabeur 1987, as well as in investigations of similar type in the 1990's, such as Al-Muhannadi 1991, Al-Wer 1991, Khtani 1992, and Al-Shehri 1993. In some cases, we find that 'education' simply refers to whether the speakers are literate or not, and in others 'education' is quantified to include lower, medium and higher levels of education. Although in these studies correlations were found between speakers' level of education and their linguistic choices, this does not ensure that education is not a proxy variable, acting on behalf of other variable(s).

Put simply, the thesis I present in this article is that in Arabicspeaking communities, it is not level of education per se which correlates with linguistic usage, rather that level of education is actually an indicator of the nature and extent of the speakers' social contacts. It just so happens, that, in the Arab World, access to education, especially 
at the higher level, and often even beyond primary schooling, involves significant alterations to individuals' socialisation patterns. It involves leaving one's home town, changes in familial links, expansion in social contacts, interaction with speakers of other dialects, exposure to different social values, shifting of one's loyalties and attachments to various social groups, changes in priorities and ambitions, etc. All of these, and others of a similar nature, are important factors in shaping individuals' linguistic behaviour. The effect of the social network as a norm enforcement mechanism, or the diminution of this effect as a result of changes in social network is demonstrated in the pioneering work of Lesley Milroy in Belfast, Northern Ireland (see L. Milroy 1980). The systematic relationship between linguistic behaviour and social network has been found also at the level of smaller social categorisations, such as adolescent friendship groups, as in Cheshire's study in Reading, UK (Cheshire 1982). Furthermore, the importance of the community members whose social contacts experience expansion and become multiplex can go beyond changes to their own linguistic behaviour. These individuals become carriers, agents of transmission, of linguistic innovations back to their home towns, or their core networks, thus making new features accessible to a wider section of the community. Their role is, in other words, also pivotal in initiating and advancing linguistic changes. What is needed to test the thesis of this article is: (i) to consider the general trends of linguistic change in Arabic, (ii) to examine the role of the 'educated' in directing the course of change, and (iii) to reexamine the data by grouping the speakers according to contact, rather than level of education. In the following sections, I shall rely on the information available in the literature on variation and change in spoken Arabic to address (i) and (ii). For (iii), the sort of details needed about the speakers' social contacts are not accessible from studies other than my own; I will, therefore, revisit my own data, presented in Al-Wer 1991.

\section{Variation and change in Arabic: general trends}

We have available a number of large scale sociolinguistic investigations in a range of Arabic communities, which mainly provide information of sound change in spoken Arabic. Although the data available mostly report alternations, and possibly change, in a few phonological variables, most crucially these data are diagnostic of a general trend of sound change in spoken Arabic. 
A good starting point, for the purpose of this discussion, is Holes' (1995) article 'Community, dialect and urbanization in the Arabic-speaking Middle East’. Holes picks up three Arabic-speaking regions, Bahrain, Jordan and Iraq, as case studies and, allowing for community idiosyncrasies, argues that the common factor of urbanisation in these regions has resulted in common patterns of dialectal use. The novel aspect of Holes' argument, in my opinion, is that it departs from the rather uninformative attempts at pinpointing the linguistic characteristics of a common Arabic norm, the only linguistic resource available in meetings between Arabic speakers from divergent dialectal regions. Occasional contexts, such as meetings between Arabs from different regions, where a number of short term linguistic adjustments might occur, are not the testing ground for linguistic change in spoken Arabic. Clearly, linguistic change in Arabic is governed by a multitude of social, political, socio-psychological and linguistic factors peculiar to each Arab society and Arabic dialect (or group of dialects). The key word in Holes' article is common patterns, not common features.

Bahrain is a speech community in which the major sociolinguistic dynamics are controlled by the asymmetrical power relation between the Arab and the Baharna social groups. A number of phonological features distinguish between the 'traditional' dialects of the dominant Arab group and the Baharna group. These include differences in: realisations of /q/, realisations of the interdental sounds, realisations of $/ \tilde{y} /$, and the phonological environments of fronting and affrication of $/ \mathrm{k} /$ (Holes 1995: 274). As a result of urbanisation and social mobility, a koineised dialect of Bahraini Arabic has emerged, which is assuming the role of a local standard and is used in Manama and elsewhere in the country. Although the salient linguistic characteristics of the emergent dialect represent levelling processes of localised (peculiar) features generally, the biggest 'loser' in this process is the Baharna dialect. In approximating to this new standard, assuming they were native speakers of the traditional dialect, the Baharna will have to acquire [g] and level out [k], acquire [k], and extend the use of [y] to cover not only the lexical items with etymological [y] but also the

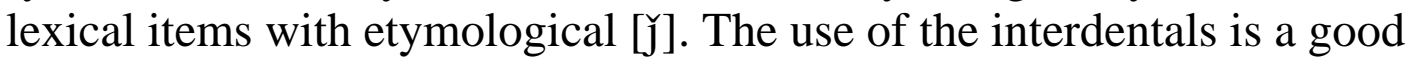
deal more complex from an acquisition viewpoint. Here, not only do the Baharna need to acquire the sounds $[\theta]$, [ð] and [ð̣], but also to split 
the lexical sets which in their traditional dialect had /f/, /d/ and /ḍ/. This process assigns $[\theta]$ to /f/ in words with etymological / $\theta /$ only, [ð] to /d/ in words with etymological /ð/ only, and [ọ] to /ḍ/ in words with etymological /ð̣/. In the case of the Arab dialect, to start with none of its traditional phonological features are actually stigmatised. And, in terms of phonological 'distance' from Classical Arabic, the Arab and the Baharna traditional dialects stand equal. The differences between the Arab dialect and the 'new' standard include only minor alterations, mainly reduction in frequency of occurrence of $(\mathrm{k})$ : [c] on this point, Holes (p276) writes "for the literate A[rab] speakers, the intercommunal dialect represents only a small shift away from the variants used by their non-literate kinsfolk”. So, in the case of Bahrain, the linguistic repercussion of increased literacy and urbanisation is not a change towards Classical Arabic features, although the perpetual agents and users of the new dialect are the literate members of the community.

In Jordan, the impetus to language change in the new urban centres, such as Amman, is, in the first place, the contact in a new context between Jordanian and Palestinian (urban and rural) dialects. A series of events, mainly of socio-political nature, have led to redefinitions of the social meanings of the use of various linguistic features. For instance, features previously associated with an oldfashioned lifestyle, such as (q): [g], has become an important symbol of 'Jordanian identity'. Although origin (in terms of Jordanian versus Palestinian) as a social parameter continues to exert influence on the linguistic situation, and is undoubtedly important in social stratification, other parameters such as gender have become prominent. It is also possible to expect that differences according to socioeconomic status will ultimately override the significance of ethnic origin as a criterion of sociolinguistic stratification. The relative importance of social parameters is never static, but tends to shift in accordance with social change in general. Urbanisation and modernisation require a certain degree of homogenisation, or normalisation of social behaviour, including the linguistic one, which ultimately blurs the original geographically-based or ethnically-based linguistic differences ${ }^{1}$. Based on studies of variation and change in Jordan, Holes (1995) lists the

\footnotetext{
${ }^{1}$ See for instance Haeri's comments on the dialect of Cairo, "a well-established urban dialect" where the factor of place of origin plays no significant role (Haeri 1996: 19).
} 
salient consonantal features most likely to become established features of the emergent dialect of Amman. In this case, we see that the loser is the rural Palestinian dialect whose demographic representation in the city's population is indisputably large, certainly not less than the other groups. No phonological feature characteristic (as a stereotype) of the rural Palestinian dialects is likely to become a feature of the focused Amman dialect. In the context of Jordan, this dialect has nothing going for it, since, in addition to being 'rural' it has no correlations with a territorially-based local identity. Put simply, the 'successful' mix rather includes features characteristic of indigenous (East Bank) Jordanian and urban Palestinian dialects. In broad terms, the emerging Amman dialect exhibits stable variability in the use of (q): [?]/[g], stop/sibilant for the interdentals, and ( $)$ ): affricate/fricative. The power relationship between the major groups here, the 'Jordanians' and the 'Palestinians' (which is a good deal more complex than the Bahrain case) is an important factor which determines the linguistic shape of Amman. However, it is equally important not to overlook koineisation processes at the level of the Levant region in general. The chances of success of the urban Palestinian features are enhanced by the fact that these are identical to the urban Levantine norm. Pressure towards regional koineisation, nonetheless, is not going to make the dialects of Beirut, Damascus, Jerusalem and Amman identical; the countries of the Levant are separate political entities with separate (and often conflicting) social and political agendas. Pressure in the opposite direction, perhaps as a reflection of the maintenance of distinctive local identity, will ensure that certain local features will be maintained. We do not see the result of this pressure at the level of consonantal change because most consonantal alternations are discrete by nature. Vocalic alternations, on the other hand, are much more gradient, and thus allow for a wider range of choices and changes. My own ongoing research on the vocalic features of Amman dialect (Al-Wer, forthcoming) suggests that in many cases, the vocalic features which characterise the speech of the current generation in Amman are not identical to any of the forms in the original mix; rather, they appear to be totally new features, often representing phonetically intermediate forms. The emergence of these features is not explainable with reference to Jordanian-Palestinian competition. They are, rather, associated with the fact that as Amman acquires a native population for the first time in the its modern history, 
it also acquires a regional identity. The youngsters of Amman nowadays refer to themselves as 'Ammaniyiin', unlike their parents who identify their origins with reference to the Jordanian or Palestinian town/village from which the extended family originally came. The new linguistic features, as well as new combinations of existing features, are symbols of this new identity.

The case of Baghdadi Arabic is another example of how the linguistic developments are primarily influenced by the relative status of the native varieties spoken by the various social groups. Holes (1995) review of this case is particularly interesting, especially in its treatment of the current (target) Muslim dialect as a historically levelled dialect itself, which came to assume dominance in the modern history of Iraq. Here, the salient phonological features involved in variation represent differences along religious lines between the two major (now) native groups of the city, the Muslims and the Christians. Broadly speaking, the change in Baghdad is in the direction of the Muslim dialect (without implying that this dialect is static either); the shift on the part of the Christians from the stereotypical Christian feature [q] (also a feature of Classical Arabic) to [g], a stereotypical feature of the Muslim dialect is most notable. The earlier investigations of Blanc (1960) indicated that the Muslim dialect was used in intercommunal situations, a finding which is symptomatic of change in progress, but, in itself, is not necessarily proof of it, since this could be a case of short-term accommodation. But, the more recent reports by Abu-Haidar (1990 \& 1991) confirm that Blanc's earlier observations did represent change in progress, since the shift from the typically Christian features towards the Muslim features has been attested in intra-communal contexts.

The findings from other studies consistently confirm the pattern that variation and change in spoken Arabic is primarily influenced by the relative status of the socially marked linguistic varieties, not by the status of linguistic features in relation to Classical Arabic; see for instance the findings regarding the interdental sounds in Al-Ahdal (1989) in Mecca, Jassem's (1993) results of six variables in Damascus, Jabeur (1987) of monophthongisation in Tunis, and Haeri (1998) of palatalisation in Cairo. Change at the morphosyntactic level follows the same pattern; for instance, gender neutralisation in the second and third person pronouns (and subsequently verb endings) in Jordanian dialects 
(Al-Wer 1991), raising of the feminine ending in Amman (Al-Wer, forthcoming), and neutralisation of second person pronoun and verb ending by immigrants in Tunis (Jabeur 1987).

Based on the phonological and morphosyntactic data available the conclusion is that linguistic change in Arabic is determined by the relative status of the native spoken varieties (which is determined by the relative status of their speakers); in this domain, the status of the linguistic features vis a vis Classical Arabic is irrelevant. No other conclusion can be as robustly supported.

\section{The leaders of linguistic change}

With respect to locating the individuals who lead and direct linguistic change, in all of the studies which included education as a speaker variable, the data show that the higher the education level of the speaker, the more advanced the change is in their speech towards the innovative forms. The behaviour of the educated speakers is consistent, regardless of whether the innovative forms are identical to or different from Classical Arabic features. In Jassem's (1993) study of the change to the dialect of an immigrant group from the Golan Hights now resident in Damascus, five of the variables involve variation between traditional immigrants' dialectal features, which are identical to Classical Arabic features, and local features stereotypical of the dialect

of Damascus. For all of these variables, it is the educated speakers who lead in the change towards the Damascus forms. The most vigorous phonological change in Jordan is the change from interdental to stop sounds; data show consistent positive correlation between level of education and use of the stop variants: the university educated speakers use the stop sounds more often than any other group. Monophthongisation of /ai/ and /au/ in Tunis is, likewise, spearheaded by the educated speakers; Jabeur (1987: 108) reports that while the traditional diphthongal realisations occur almost categorically in the speech of the illiterates, they are totally absent from the speech of the young educated speakers, leading to loss of phonemeic contrasts (for details, see Jabeur 1987: 111). In the same study, the data on all but one of the morphosyntactic features investigated show that the educated speakers lead the change towards local urban Tunisian features (Jabeur 1987: 197-99). 
The pattern is consistent in showing that there is an inverse correlation between level of education and use of Classical Arabic features when these features are different from the target, highly rated, local and prestigious features. This happens not because the educated speakers want to abandon Classical features, but because Classical Arabic as a variety is irrelevant in this domain. Since the determinant(s) of the success of a linguistic change is not how similar the feature involved is to a Classical Arabic feature, proficiency in Classical Arabic, and its determinants, such as formal education, is not the best parameter of speaker categorisation.

It seems that in academic practice, the choice of 'education' as a speaker variable is based on the assumption that standardisation, or approximation to Classical (Standard) Arabic directs the course of linguistic change in spoken Arabic. But, since this has been shown to be erroneous by empirical data, an alternative model of speaker selection and grouping is needed.

\section{The data}

The results upon which the following discussion is based are taken from a sociolinguistic study which investigated phonological variation in the provincial towns of Sult, Ajloun and Kerak in Jordan with a sample of 116 women speakers, and reported in detail in Al-Wer (1991). A total of approximately 60 hours of taped material was collected using sociolinguistic interviews, representing casual free speech. By way of illustration, I will look at variation in the use of the variable $(\theta)$ in the town of Sult, which lies some 25 kilometres to the north west of Amman. Similar to all other indigenous Jordanian dialects, in the local dialect of Sult, $(\theta)$ is realised as $[\theta]$ (as in Classical Arabic). The variation attested in the use of this variable involved mainly $[\theta]$ and [t], and was found exclusively in women's speech.

There are no phonological constraints on the alternation between $[\theta]$ and [t]. The two sounds occurred in the same phonological environment: initially, as in [ $\theta$ aani]/[taani], medially (in consonant

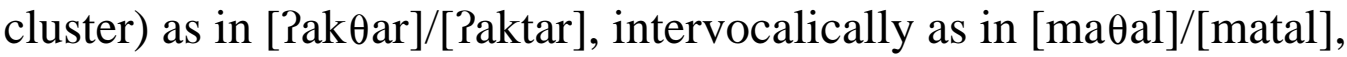
and word finally as in [baia $\theta] /[$ baSat]. Nor is the alternation strictly constrained by the status of the lexical item in terms of 'standard' versus 'vernacular'. The variants $[\theta]$ and $[t]$ were used, often by the same speaker, in words which can be considered 'standard', such as:

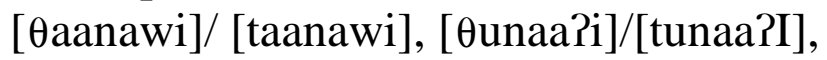




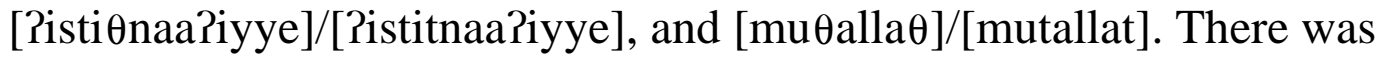
one word, and its derivations, which were used consistently with [ $\theta]$,

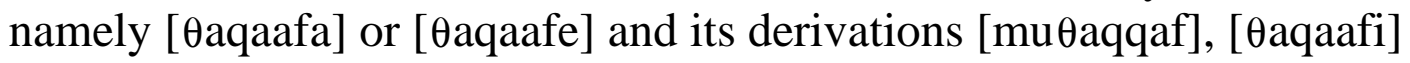
and [ $\theta$ aqaafiyye], in addition to one religious reference [Hadii $\theta$ ], referring to the prophet's sayings, and the specialised expressions [wiraa $\theta \mathrm{e}$ ], referring to genetics, and [?albaH $\theta$ ], referring to the Department of Scientific Research. These items were excluded from the quantification of the relative frequency of the occurrence of the two variants, since the occurrence of $[\theta]$ in these items appeared to be lexically conditioned ${ }^{2}$.

Table 1 below shows the use of the innovative feature [t] (corresponding to Classical Arabic $[\theta]$ ) amongst the speakers, grouped according to three educational categories.

Table 1: Use of [t] by level of education

\begin{tabular}{ll}
\hline Level of education & $\%$ use of $[\mathrm{t}]$ \\
\hline Highly Educated & $59 \%$ \\
School educated & $43 \%$ \\
& \\
Uneducated & $7 \%$ \\
\hline
\end{tabular}

These statistical data appear to show correlation between the speakers' level of education and their use of the innovative feature, with the highest educational group, the university or college educated speakers, showing the most advanced usage of [t] while, in this respect, the lowest educational group, the illiterate speakers or those with minimal education considerably lag behind. Why grouping the speakers

\footnotetext{
${ }^{2}$ The alternation between [ $\left.\theta\right]$ and [t] in Jordan is quite different from the use of $[q]$ alongside $[\mathrm{g}]$ or [?]. The former case is clearly a change in progress, i.e. the increase in the use of [t] reflects a decrease in the use of $[\theta]$; the few cases reported here, where there was no alternation between the two sounds, is an indication of the way in which the change progresses. Lexical items in these categories, religious and specialised expressions, are, for obvious reasons, transferred at a slower rate. But, in the case of (Q), an increase in the use of [q] is not mirrored by a decrease in the use of [g] or [?]; all of the lexical items in which [q] is used fall in the category of specialised items, which do not show [q]/[g] or [?] alternation. The lexical conditioning in the use of [q] is not peculiar to Jordan, and has been found elsewhere in the Arab world, but the Jordanian case is particularly clear since there is no local dialect whose normal reflex of $(Q)$ is $[q]$. Strictly speaking, the variation in the use of (Q) in Jordan involves [g] and [?] only.
} 
according to level of education should give us this pattern is not clear from these data. Closer examination of the behaviour of the speakers individually reveals different correlational patterns. Figure 1 below shows the individual scores of [t] by the highest educational group.

\section{INSERT FIGURE 1 HERE}

In the extent to which they use [t], these speakers vary considerably: from consistent use of the innovative feature to consistent use of the local feature, with most speakers being clustered between 54\% and $81 \%$ use of [t]. Without ignoring the relative importance of the factor of age, we notice that age alone is not the whole story. In particular, the factor of age does not explain the distribution at the polar ends of the figure. At the lower end, the two speakers who used the local feature consistently belong to the older age group (48 years and above at the time of the research), but there are three younger speakers whose scores of $[t]$ are also fairly low. At the top end, there are two younger speakers (both aged 27 years) and one older speaker who used the innovative feature close to categorically. Roughly, the clustering in the middle is made up of half of the speakers from each age group, 6 speakers out of 11 in the case of the younger group, and 4 speakers out of 7 in the case of the older group. In quantitative analysis, the behaviour of a minority of speakers at the top and bottom ends is blurred. But often illuminating explanations can actually lie in the behaviour of these 'exceptional' speakers.

There are three speakers who are most responsible for skewing the group's average upwards towards more use of [t], namely speakers 1, 2 and 12. Their average use of the innovative feature is $95 \%$. Speaker 1 was 27 years old at the time of the research. She was educated at an Arab university abroad for 5 years, and underwent a further training course in an English-speaking country. When she was interviewed, she had just arrived back home, and was as yet unemployed. Her social contacts in the town were limited to members of her extended family, but because of the length of time she had been away from the town, she had no close friends locally. She mainly socialised with the friends she had known at university, all of whom lived in Amman. She was also seeking employment in Amman not in Sult. Although speaker 1 came from a large and well-known local 
family, her future plans were clearly not locally oriented. Speaker 2 was also 27 years old at the time of the research. She had a degree in dentistry from an Arab university abroad, and had been employed locally for 3 years. Like Speaker 1, she had frequent and regular contact with friends in Amman with whom she spent most of her leisure time. Locally, she was closely acquainted with and worked in the same place as Speaker 4 (see Figure 1). Speaker 2 was particularly critical of the town and the local community; she neither enjoyed living there, nor appreciated the benefits of a close-knit community. Speakers 1 and 2 had similar backgrounds and very similar outlooks. Speaker 12 was 50 years old, and was also educated at an Arab college abroad. She had held a job locally for 18 years and was retired at the time of the research. Although she had lived all her life in Sult, and worked there for many years, she maintained that she kept very few contacts with the local community. She and her family had moved to the suburbs a few years earlier, and she was not a member of any local organizations. The only other member of the community with whom she exchanged visits was Speaker 14. Her brothers and sisters all lived in Amman. She visited them weekly, shopped in Amman, and even sent her children to schools in Amman. To her, the town and the local community represented an outdated lifestyle. The divergent behaviour of these speakers from the local feature can be interpreted as the linguistic symbol of their desire to dissociate themselves from the local community. At the other end, we have speakers 9 (27 years old), 10 (28 years old), and 11 (33 years old). These speakers studied at a university in Amman, and had been locally employed for a few years. Also in this group are the most conservative speakers, Speakers 17 (50 years old) and 18 (48 years old), who used the local feature categorically. Speakers 17 and 18 had a higher degree from an Arab university abroad, and had worked locally for 18 years. The local contacts and the relationships of this group of speakers with the local community were totally different from the more innovative speakers above. Most notably, they had a wide circle of local friends with whom they met regularly; they were also active members of local charity organizations, and sports clubs. The use of the local dialect can also be associated with local issues. For instance, although these speakers too were critical of many things about the town, and the local community, they were simultaneously prepared to participate in local politics. Their daily 
activities were very much centred locally; their future plans and those for their children were also locally oriented.

Under a classification on the basis of contact with speakers of the target feature, and relationship with the local community, Speakers 1,2 and 12 represent the members of the community with the highest opportunity of access to the target feature (through regular and frequent contact). They are also least embedded in the local community (and thus least bound by local norms). Their group score is $95 \%$ use of [t], which is considerably higher than the average for the highly educated group (which is 59\%). Speakers 9, 10, 11, 17 and 18 represent the group whose members have less regular contact with speakers of the target feature, and are most locally oriented. Their score is $15 \%$ use of [t], which is closer to the score for the illiterate group (7\% of [t]) than it is to the average score for the highly educated speakers. Thus, it appears to be the case that the primary determinants of the correlation have to do with contact patterns and relationship with the local community (not with education as such).

By the nature of things, in communities which are in transition to urbanisation and urban-based economy, formal education is the main channel through which individuals' outside contacts are expanded. Thus, we often find that the speakers in the lowest educational group generally have limited outside contact. In the Sult sample, there are 10 speakers in the lowest educational group. As a group, these speakers were the most conservative, in the sense that they used the local features (of all variables) most often (and nearly categorically). Most of them were unemployed and rarely travelled outside the town. But looking at the scores of the speakers in this group individually, one speaker in this group stands out clearly as an innovator: she scored $72 \%$

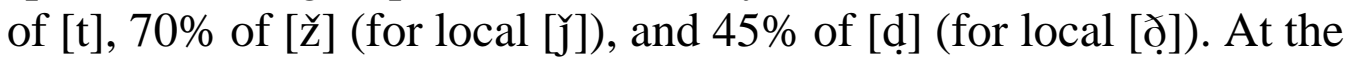
time of the research, she was 21 years old, and was employed as a caretaker at (the newly opened) university college on the outskirts of Sult. Compared with the other speakers in this group, she had more opportunity of access to (trendy) linguistic innovations through daily interaction with young college students, and with members of staff in the college. And particularly because of her young age, the convergence in her speech towards that of the younger generation is not 
surprising $^{3}$. In a model based on access to the target features and contact, rather than educational level, this speaker would not be exceptional; there is a meaningful correlation between amount of variation in her speech and her social characteristics.

The effect of contact patterns is also demonstrated in the scores of the speakers in the middle educational group (the school educated). Here too, individual scores vary considerably, as illustrated in Figure 2.

\section{INSERT FIGURE 2 HERE}

Interestingly, the four speakers who maintained a consistent use of the local feature were all in their 20's; speakers 11,12,13 and 14 had known one another since childhood, and had worked together in a post office for a few years. Outside work, they had a regular weekly get together. Their network was based on shared interests, beliefs, outlook and lifestyle, and similar social backgrounds. In L. Milroy's terms, this group represents a (locally-oriented) tightly-knit social network, which protects and supports its members, and acts as a mechanism which enforces adherence to the groups social norms, including the linguistic norm. The maintenance of the local linguistic features is an important symbol of belonging to, and assertion of one's status in the group ${ }^{4}$. At the top end, we have speaker 1 (36 years old) who used the innovative feature categorically, and speakers 2 (54 years), 3 (49 years) and 4 (37 years) whose score of [t], 77\%, is considerably higher than the group's average (43\%). The common factor between these speakers is frequent outside contact, with friends and members of their family who live and/or commute to Amman.

\section{Conclusion}

I have argued that level of education as a speaker variable is a proxy variable, which acts on behalf of, mainly, amount and nature of contact with speakers of the target features. The reason that classifying speakers according to level of education has thus far provided

\footnotetext{
${ }^{3}$ The case of this speaker is reminiscent of the linguistic developments in the speech of young (illiterate) housemaids who are usually brought by their families at a very young age to live and work in the homes of urban wealthy families in Amman. Informally, one observes that after a short period of time, they acquire the dialects spoken by the youngsters of the families for whom they work.

${ }^{4}$ Belonging to a close-knit network does not always result in adherence to the local norm of speech; close-knit networks can also be supra-locally oriented.
} 
researchers with fairly accurate results, especially in terms of locating the social groups who initiate and/or diffuse new features, is that in the Arabic-speaking communities, particularly those with a recent history of urbanisation, education is the major channel through which members of the community have opportunities of contact with the speakers of the target features. When this developmental phase is completed, i.e. once these communities are established as urban societies with urban-based economy and structure, where education is not necessarily a prerequisite for mobility and contact, level of education will no longer be capable of reflecting the true determinants of linguistic variation and change.

\section{REFERENCES}

Abdel-Jawad, Hassan. 1981. Lexical and phonological variation in spoken Arabic in Amman. Ph.D. dissertation, University of Pennsylvania.

Abu-Haidar, Farida. 1990. "Maintenance and shift in the Christian Arabic of Baghdad. ZAL, 21: 47-62. 1991. Christian Arabic of Baghdad. Wiesbaden: Harrassowitz.

Al-Ahdal, H. 1989. A sosiostylistic description of speech in Mekkah. PhD. thesis, University of Reading.

Al-Muhannadi, Muneera. 1991. A sociolinguistic study of women's speech in Qatar. Ph.D. thesis, University of Essex, Colchester.

Al-Shehri, Abdullah. 1993. Urbanisation and linguistic variation and change: $a$ sociolinguistic study of the impact of urbanisation on the linguistic behaviour of urbanised rural immigrants in Hijaz, Saudi Arabia. Ph.D. thesis, University of Essex, Colchester.

Al-Wer, Enam. 1991. Phonological variation in the speech of women from three urban areas in Jordan. Ph.D. thesis, University of Essex, Colchester. . 1997. "Arabic between reality and ideology". International Journal of applied Linguistics 7:2.251-265. . Forthcoming. "Jordanian and Palestinian dialects in contact: vowel raising in Amman”. Patterns of Linguistic Convergence and Divergence, ed. By M. Jones and E. Esch. Mouton.

Blanc, Haim. 1964. Communal dialects in Baghdad. Massachusetts: Harvard University Press.

Cheshire, Jenny. 1982. Variation in an English Dialect. Cambridge: Cambridge University Press.

Eckert, Penelope. 1989. Jocks and Burnouts: Social Categories and Identity in the High School. New York: Teachers College Press. 
. 1999. “Gender and Sociolinguistic Variation”. Language and Gender ed. by J. Coates, 64-75. Oxford: Blackwell.

Haeri, Niloofar. 1987. "Male/Female differences in speech: an alternative interpretation”. Proceedings of the Fifteenth Annual Conference on New Ways of Analyzing Variation. Stanford University. . 1997. The siciolinguistic Market of Cairo: Gender, Class, and Education. London: Kegan Paul International.

Holes, Clive. 1987. Language Variation and change in a Modernising Arab State. London: Kegan Paul International. . 1995. "Community, Dialect, and Urbanization in the Arabic-speaking Middle East”. BSOAS, 58: 270-87.

Ibrahim, Muhammad Hassan. 1986. "Standard and Prestige Language: a Problem in Arabic Sociolinguistics. Anthropological Linguistics, 28.1: 115-26.

Jabeur, Muhammad. 1987. A Sociolinguistic study in Tunisia: Rades. Ph.D. thesis, University of Reading.

Jassem, Zaidan Ali. 1993. Impact of Arab-Israeli Wars on Language and social Change in the Arab World: the Case of Syrian Arabic. Kuala Lampur: Pustaka Antara.

Khtani, Ali. 1992. The impact of social change on linguistic behaviour: phonological variation in spoken Arabic, Asir, Saudi Arabia. Ph.D.thesis, University of Essex, Colchester.

Labov, William. 1972. Sociolinguistic Patterns. Philadelphia: Philadelphia University Press.

Milroy, Lesley. 1980. Language and Social Networks. Oxford: Blackwell. . 1987. Observing and Analysisng Natural Language. Oxford: Blackwell.

Milroy, Lesley, and James Milroy. 1992. "Social network and social class: toward an integrated sociolinguistic model”. Language in Society 21: 1-26.

Schmidt, Richard. 1974. Sociolinguistic Variation in Spoken Egyptian Arabic. A Re-examination of the Concept of diglossia. Ph.D. dissertation, Georgetown University.

Trudgill, Peter. 1974. The Social Differentiation of English in Norwich. Cambridge: Cambridge University Press. 